\title{
Design and Manufacture of a Frame for a Small Electric Motorcycle
}

\author{
Jozef Macej, Peter Michalik, Peter Tirpak \\ Faculty of Manufacturing Technologies with a seat in Presov, Technical University of Kosice, \\ Sturova 31, 08001 Presov, Slovakia
}

\begin{abstract}
This article deals with the theoretical basis for the design of a motorcycle frame such as the geometry of the motorcycle, the choice of the shape of the frame and the choice of material for the manufacture of the frame. The article is devoted to the use of simulation tools to detect critical points in the design using Autodesk Inventor 2020 software. The results of the simulations were used in the production of a real frame for an electric motorcycle.
\end{abstract}

Keywords - electric motorcycle, motorcycle frame, simulation, optimalisation, production

\section{Introduction}

Electromobility is currently a very frequent topic due to the efforts to reduce air pollution, especially in urban areas. However, electric vehicles are not hot news. The first mentioning of electrically powered vehicles dates from the end of the 19th century. In Figure 1. you can see one of the first electric bicycles which was patented in 1985 by the American Ogden Bolton. Bolton's electric bicycle had an electric motor located in the rear wheel hub. This solution was revolutionary and is still used today [1].

\section{DOI: $10.18421 /$ SAR42-05}

https://doi.org/10.18421/SAR42-05

Corresponding author: Jozef Macej,

Technical University of Kosice, Faculty of Manufacturing

Technologies with a seat in Presov, Sturova 31, 08001

Presov, Slovakia.

Email: jozef.macej@tuke.sk

Received: 08 April 2021.

Revised: 12 June 2021.

Accepted: 17 June 2021.

Published: 27 June 2021.

(C) 2021 Macej Jozef, Michalik Peter \& Tirpak

Peter; published by UIKTEN. This work i $s$ licensed under the CCBY-NC 4.0 licence.

The article is published with Open Access at www.sarjournal.com

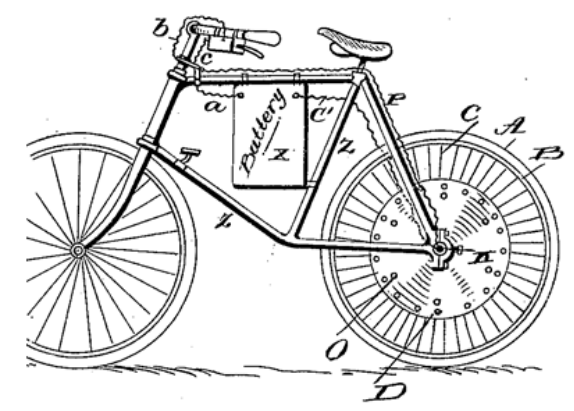

Figure 1. Electric bicycle patented in 1985 [1]

The biggest problem with electric vehicles has always been energy storage. In the past, the bestknown lead-acid batteries were characterized by low energy density. This means that the batteries were heavy for practical use and provided only a short range of the vehicle. Due to the mentioned shortcomings of the batteries, the electric vehicles were pushed into the background compared to the vehicles with internal combustion engines for a very long time. Recent advances in battery technology have made the idea of electromobility possible. Lithium-ion batteries are currently the most widely used in the field of electromobility, due to the constantly falling price [2], constantly improved energy density and relatively long life [3]. Developments in technology show that electromobility has the potential to become an everyday reality. At our University, we decided to build our own prototype of an electric motorcycle, which would be usable mainly for transport in a city. This motorcycle should be the basis for further research and improvements in the field of electromobility at our University.

\section{Motorcycle Geometry}

The riding characteristics of the motorcycle, manoeuvrability, but also riding safety, mainly depend on the geometry of the motorcycle. The main parameters of the geometry of the motorcycle are shown in Figure 2. 


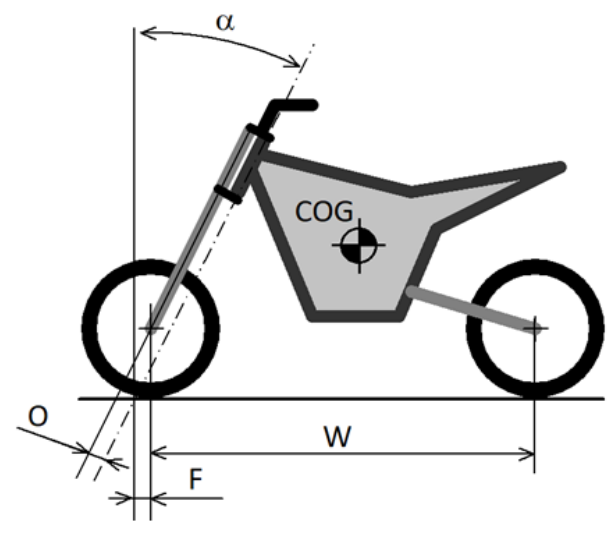

Figure 2. Motorcycle geometry

The position of the centre of gravity (COG) of the motorcycle depends not only on its construction, but also on the position of the rider. In general, if the centre of gravity is lower, the motorcycle is easier to control, especially at lower speeds. At higher speeds it is more advantageous to have the centre of gravity of the motorcycle shifted higher from the point of view of stability. If the centre of gravity of the motorcycle is shifted more towards the front, this will suppress the tendency for the handlebars to oscillate, but the handling of the motorcycle will be worse. On the other hand, when shifting the center of gravity towards the rear of the motorcycle, manoeuvrability improves, but at the expense of the vibration of the handlebars, especially at a large rake angle $(\alpha)$ [4].

The rake angle $(\alpha)$ indicates the inclination of the front fork relative to the axis perpendicular to the ground. Typically, this angle is in the range of $23^{\circ}$ to $30^{\circ}$ [5]. Depending on the type of the motorcycle, the rake angle is selected. City scooters and sports motorcycles have a rake angle smaller than chopper motorcycles. A smaller rake angle increases manoeuvrability, for example in urban conditions.

The displacement of the front wheel axle away from the steering axis is called offset $(\mathrm{O})$. The intentional displacement of the wheel axle forward from the steering axis achieves automatic stabilization of the front wheel position in a straight line, for example when passing on uneven roads. When cornering, the motorcycle tends to return the front wheel to the centre position and steer the motorcycle in a straight line. Theoretically, if the rider releases the handlebars of the motorcycle while riding, the motorcycle should continue to ride in a straight line, the position of the handlebars should be stabilized in the middle.

The front trail $(\mathrm{F})$ is the most important factor that determines the stability of the motorcycle, especially when driving fast in a straight line. It typically ranges from 50 to $100 \mathrm{~mm}$ [5]. In general, when the front trail is longer, it is easier to keep the motorcycle moving in a straight line. On the other hand, with a longer front trail it is more difficult to manoeuvre the motorcycle in a sharp turn. The right choice of front wheel track length is often a compromise between the stability and agility of the motorcycle.

The distance between the wheel axles is called the wheelbase (W). As the wheelbase increases, the directional stability of the motorcycle increases, but on the other hand, the difficulty of operating the motorcycle when cornering also increases. The wheelbase ranges from approximately $1270 \mathrm{~mm}$ for small motorcycles to $1400 \mathrm{~mm}$ for larger and faster motorcycles [5].

The stability of a motorcycle depends on many factors, such as properly inflated tires [6] and motorcycle suspension. Variable geometry suspension systems help increase stability when changing motorcycle loads and also prevent dangerous motorcycle oscillations at high speeds [7].

We designed our motorcycle for use in urban conditions, where good manoeuvrability at low speeds is required. Therefore, we chose a small steering angle $\alpha=20^{\circ}$ and a small wheelbase $\mathrm{W}=1250 \mathrm{~mm}$. We wanted to place the centre of gravity of the motorcycle in the middle and as low as possible.

\section{Motorcycle Frame}

The most important properties of a motorcycle frame that we considered when choosing a material for the production of the frame are strength, stiffness and weight. One property also excludes another. For example, it is not easy to make a high-strength frame that is ultra-light. The choice of material for the frame is also influenced by other factors such as material availability, price, machinability, fatigue resistance, the possibility of welding etc. Therefore, the choice of material is a compromise between requirements and possibilities. In the world of motorcycles, as in the world of bicycles, the most commonly used frame materials are steel, aluminium alloys and carbon fibre composites. Structural steel is still the most widely used material, especially in the case of mass-produced cheap motorcycles. The advantage of structural steel is excellent availability in the form of tubes and plates. Steel machining and welding technologies are well developed and commonly available. Young's modulus of steel is higher compared to aluminium, so the required stiffness can be obtained with small tube sizes [5]. Many motorcycle manufacturers use chromiummolybdenum steel to build frames, which has the same Young's modulus and density but higher strength than structural steel. In the case of the use of high-strength steels, it is possible to reduce the weight of the frame by using tubes with thinner walls compared to structural steel. The strength of the 
frame is maintained, the weight is reduced, but the stiffness of the frame is also slightly reduced [5]. Aluminium alloys are used to make frames in the form of plates and castings of larger dimensions, which are welded together. Occasionally we can meet with a tubular frame made of aluminium alloy. Compared to steel tubes, aluminium tubes must have significantly thicker walls to compensate for their low Young's modulus if we want the same rigidity of the frame. It should be considered that aluminium has a lower fatigue resistance than steel [5]. Aluminium alloy frames are mainly used for racing machines and motorcycles of higher price categories. Frames for motorcycles completely made of composite materials based on carbon fibres are currently a rarity due to very demanding and expensive production. Therefore, only the bonnet, mudguards, or wheel rims are produced from composite materials based on carbon fibres. There are also examples where a main steel frame and composite subframes are combined [8].

Our motorcycle is designed for the category of scooters for urban use. Therefore, we chose a step through frame. The free space between the seat and the handlebars allows the rider to sit comfortably on the motorcycle. Before we started designing the frame, we selected the necessary motorcycle components such as the battery, the BLDC motor, the BLDC motor controller, the brake systems and front and rear suspension systems etc. We first considered a monocoque motorcycle frame that would protect the motorcycle's battery and electronics from mechanical damage, rain and dust. Our first motorcycle design is shown in Figure 3.

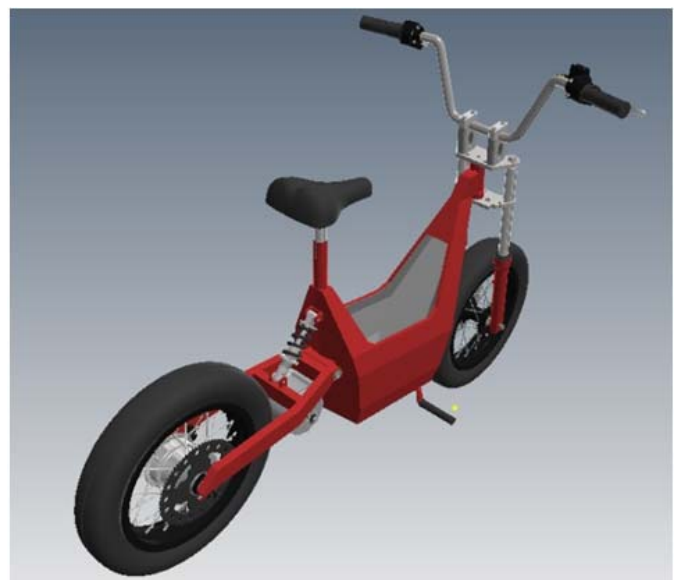

Figure 3. Monocoque construction design

We planned to use steel or aluminium alloy plates for the production of the monocoque frame.
However, the production of such a frame is difficult and requires a lot of welding. Another problem with this frame is the difficult access to the components installed in the frame. Therefore, we decided to modify the design of the frame. Round tubes are most often used for the construction of frames. Their advantage is the same rigidity in all directions. The disadvantage of round tubes is the need to shape the ends of the tubes, for example if we want to connect two round tubes into a T-shape. From this point of view, it is easier to use square tubes. The design of the tubular frame is shown in Figure 4.

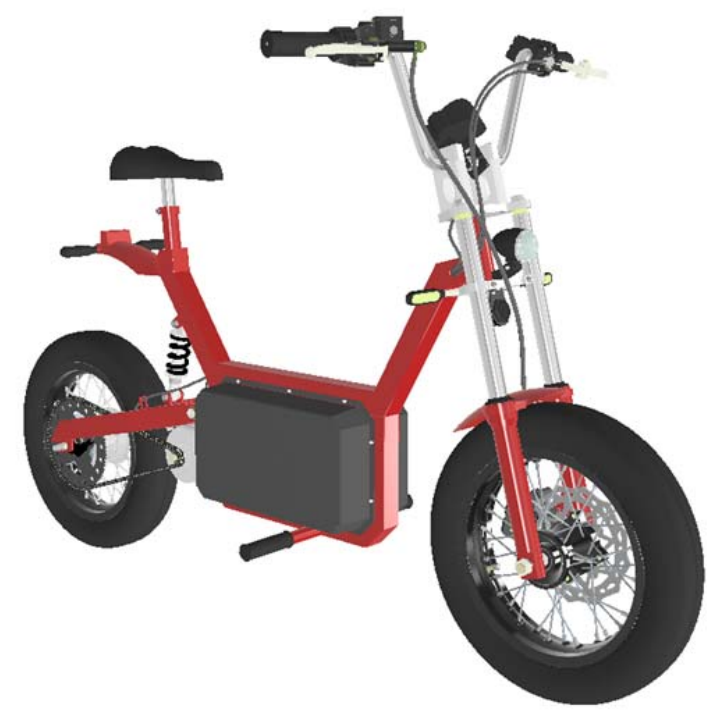

Figure 4. Tubular frame design

For the production of the frame, we chose popular general construction and machine structural steel grade S235JR. This steel is commonly available in the form of various rods, tubes and plates. The steel is weldable without restriction. Chemical composition of steel S235JR for thickness not exceeding $40 \mathrm{~mm}$ is shown in the following table [9]:

Table 1. Chemical composition of S235JR steel [9]

\begin{tabular}{|c|c|c|c|c|c|}
\hline $\mathrm{C}(\%)$ & $\mathrm{Mn}(\%)$ & $\mathrm{P}(\%)$ & $\mathrm{S}(\%)$ & $\mathrm{N}(\%)$ & $\mathrm{Cu}(\%)$ \\
\hline$\leq 0,17$ & $\leq 1,4$ & $\leq 0,035$ & $\leq 0,035$ & $\leq 0,12$ & $\leq 0,55$ \\
\hline
\end{tabular}

For thicknesses less than or equal to $16 \mathrm{~mm}$, steel S235JR at temperature $20^{\circ} \mathrm{C}$ reaches the strength limit $\mathrm{R}_{\mathrm{m}} 360-510 \mathrm{MPa}$ and minimum yield strength $\mathrm{R}_{\mathrm{EH}} 235 \mathrm{MPa}$ [9].

Figure 5. shows the individual parts of the frame. The main production material is a tube with a square cross-section with a wall thickness of $2 \mathrm{~mm}$. 


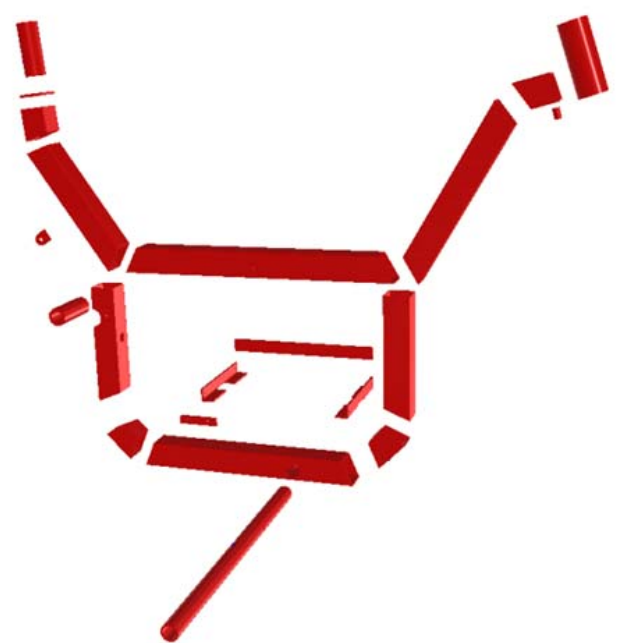

Figure 5. Individual parts of the frame

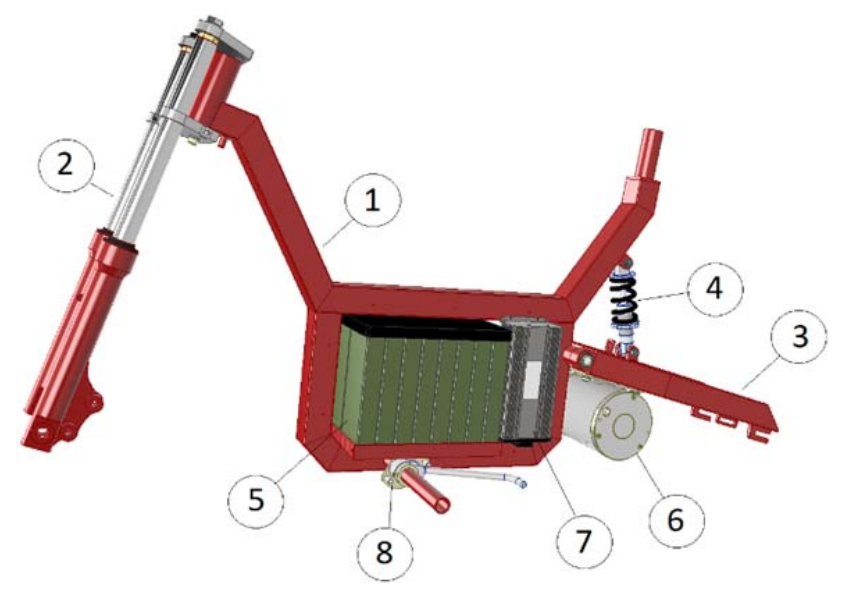

Figure 6. Motorcycle frame and basic components

Figure 6. shows the assembled tubular frame (1) of the motorcycle and the most important components of the motorcycle such as the steering and front suspension system (2), the rear swingarm (3), the rear suspension system (4), the battery (5), the BLDC electric motor (6) and the controller (7), the footrests and the tilting stand (8). The BLDC motor is mounted on the rear swingarm. This solution has the advantage that the roller chain between the motor and the rear wheel is constantly tensioned during the rotation of the rear swingarm. One of the advantages of a tubular frame is the ability to place electrical cables and brake hoses inside the frame and thus protect them. The flat surfaces of the frame allow easy installation of side covers with seals to protect the battery and electronics from water and dust. The side covers can be made of carbon fibre-based composite materials to make the motorcycle lighter.

\section{Frame Stress Analysis}

We performed stress analyses on the designed frame to identify critical design points. We tried to simulate the real loading of the frame at a constant speed of movement, during acceleration and during deceleration. We used Autodesk Inventor Professional 2020, which offers finite elements analysis.

We started by creating a model for dynamic simulation. The model included a steel tubular frame with a front suspension/steering system, a rear swingarm with a suspension system as can be seen in Figure 7. The upper and lower parts of the front suspension fork were connected by translational joints and springs with a stiffness of $50 \mathrm{~N} / \mathrm{mm}$ were placed between them. The suspension of the rear swingarm consists of two parts which are connected by a translational joint and a spring with a stiffness of $300 \mathrm{~N} / \mathrm{mm}$. The axles of the wheels were attached to the auxiliary plane so that they could not move.

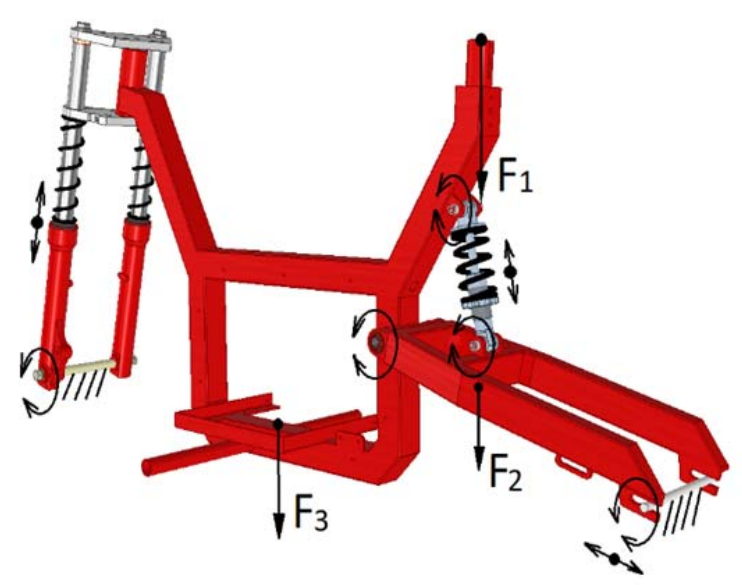

Figure 7. Model for frame stress analysis with gravity load

First, we examined the load of the motorcycle frame by the rider with a mass of $100 \mathrm{~kg}$, a mass of the electric motor of $10 \mathrm{~kg}$ and a mass of the battery of $15 \mathrm{~kg}$. Forces $F_{1}=1000 \mathrm{~N}, F_{2}=100 \mathrm{~N}$ and $F_{3}=$ $150 \mathrm{~N}$ were applied to the frame, which approximately represent the weight of the driver, the motor and the battery. This simplified distribution of forces represents a situation where the driver is sitting on the seat, either while the motorcycle is stationary or while moving at a constant speed. The effect of the mass of the other components was neglected. From the dynamic simulation, we exported FEA (Finite Element Analysis) data at the time and position when the system is in a steady state after loading with forces $F_{1}, F_{2}$ and $F_{3}$. The FEA data are further used in linear static stress analysis. In linear static analysis, the effect of external loading of a structure or component is analysed. Displacements, deformations, stresses and reaction forces are considered. We assume that all loads are applied slowly and gradually until their amplitude is reached. We consider the linearity between load and induced responses [10]. In Figure 8. we can see the Von 
Mises stress results. Red areas, signalling the occurrence of the highest stress, appear mainly in places where the structure bends.

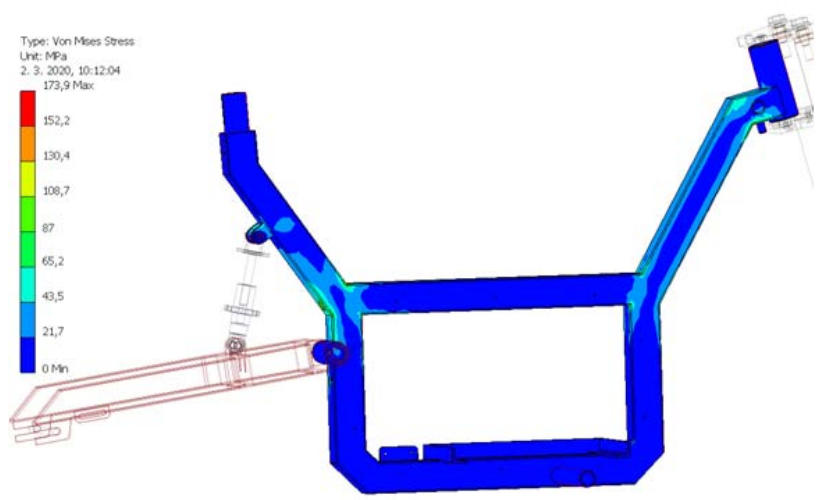

Figure 8. Frame stress analysis with gravity load, $2 \mathrm{~mm}$ tube wall thickness

The maximum achieved value of stress in the simulation was $173,9 \mathrm{MPa}$. Steel grade S235JR has minimum yield strength of $235 \mathrm{MPa}$. The ratio between the material yield strength and the maximum stress should be as high as possible. This ratio is also called the safety factor. In our case, the safety factor is 1,35 . In practice, a safety factor in the range of 2 to 4 is used. We decided to achieve a factor greater than 3 . Therefore, we increased the wall thickness of the tube profiles from $2 \mathrm{~mm}$ to $3 \mathrm{~mm}$.

Figure 9. shows Von Misses results for gravity load when tubes with a wall thickness of $3 \mathrm{~mm}$ were used. The highest value of stress was 105,3 MPa. The safety factor was increased from 1,35 to 2,23 . The weight of the frame increased from $5,715 \mathrm{~kg}$ to 7,56 $\mathrm{kg}$.

To increase the strength of the frame we decided to make the most stressed places of the frame stronger with reinforcements. In Figure 10. you can see the simulation results for a gravity loaded frame made of tubes with a wall thickness of $3 \mathrm{~mm}$ with reinforcement in the most stressed areas. The highest value of stress was $56,97 \mathrm{MPa}$. The safety factor has been increased to a value of 4,12 thanks to the reinforcements, while the weight increased by 400 grams.

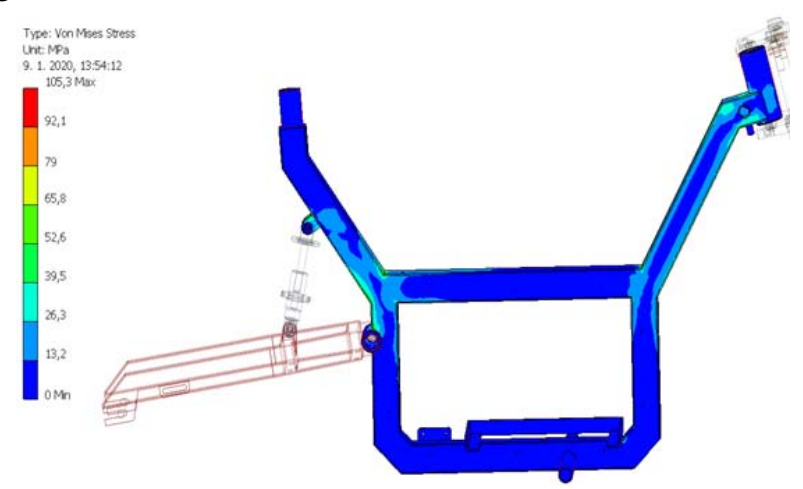

Figure 9. Frame stress analysis with gravity load, $3 \mathrm{~mm}$ tube wall thickness

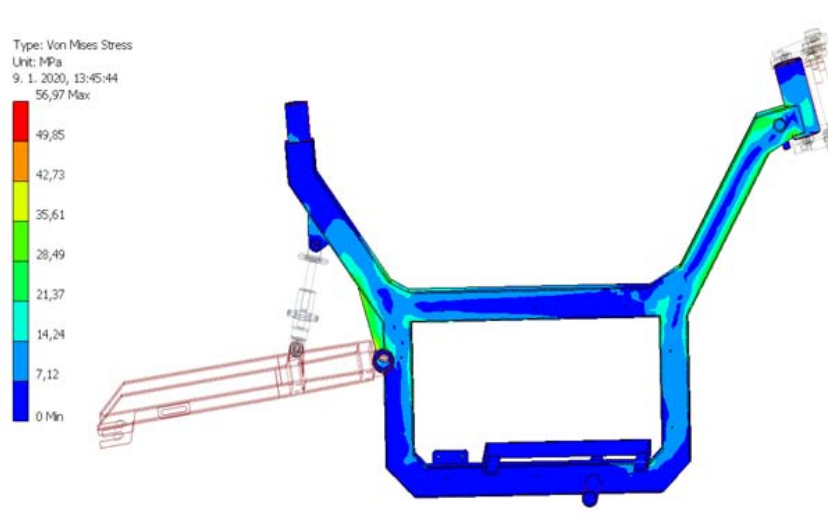

Figure 10. Frame stress analysis with gravity load, $3 \mathrm{~mm}$ tube wall thickness, with reinforcements

The results of previous analyses are summarized in the following table:

Table 2. Static frame stress analyses with gravity load

\begin{tabular}{|l|c|c|c||}
\hline \multicolumn{1}{|c|}{ Frame version } & $\begin{array}{c}\text { Max. stress } \\
\text { (MPa) }\end{array}$ & $\begin{array}{c}\text { Safety } \\
\text { factor (-) }\end{array}$ & $\begin{array}{c}\text { Weight } \\
\text { (kg) }\end{array}$ \\
\hline \hline $\begin{array}{l}\text { Tube wall thickness } \\
\text { 2mm }\end{array}$ & 173,9 & 1,35 & 5,715 \\
\hline $\begin{array}{l}\text { Tube wall thickness } \\
\text { 3mm }\end{array}$ & 105,3 & 2,23 & 7,56 \\
\hline $\begin{array}{l}\text { Tube wall thickness } \\
\text { 3mm with } \\
\text { reinforcements }\end{array}$ & 56,97 & 4,12 & 7,96 \\
\hline
\end{tabular}

From the point of view of fatigue life, it is important to reduce maximum stress. If the material is repeatedly stressed and relieved and the stress often has values less than the tensile strength, the material fatigue occurs after a certain number of cycles. Material fatigue can culminate in fatigue cracks that expand to critical dimensions, where the component is weakened to the point that it is unable to withstand the load, which can lead to fracture [11]. The probability of fatigue cracking is highest at the places of the highest stress, which can be detected by static linear stress analysis. Welded joints between individual structural segments are stress concentrators and can have a fatigue limit much lower than the fatigue limit of the base material [12].

In further analyses, we decided to consider only pipes with a wall thickness of $3 \mathrm{~mm}$ and reinforcements at the most stressed points of the frame.

We analysed the stress of the frame when the driver stands with all his mass on the footrests of the motorcycle. We assumed that the motorcycle was moving at a constant speed. We considered the driver's mass to be $100 \mathrm{~kg}$, so each footrest is loaded with a weight of $500 \mathrm{~N}$ - forces $\mathrm{F}_{1}$ and $\mathrm{F}_{2}$. The forces $F_{3}(100 N)$ and $F_{4}(150 N)$ acting on the frame represent the weight of the electric motor and the battery. The dynamic model of the motorcycle has not changed. Only the distribution of the forces has changed, as you can see in Figure 11. 


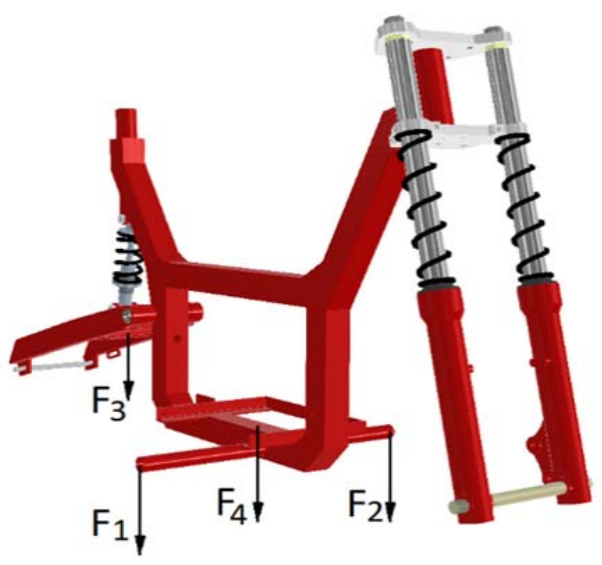

Figure 11. Distribution of forces when the driver is standing on the footrests of the motorcycle

Figure 12. shows Von Misses results for gravity load in the case of standing on the footrests of the motorcycle. The maximum stress was $136,2 \mathrm{MPa}$. This value is not critical, but it would be better to use tubes with thicker walls to make footrests. In case the driver is standing on the footrests and the motorcycle is going through an uneven road surface, the footrests will be exposed to a higher load.

When analysing the frame during sharp braking, we considered a uniformly slowed motion of the motorcycle from the speed of $50 \mathrm{~km} / \mathrm{h}^{-1}$ to the speed of $0 \mathrm{~km} / \mathrm{h}^{-1}$ in a period of $2 \mathrm{~s}$, which corresponds to the deceleration of $6.94 \mathrm{~m} / \mathrm{s}^{-2}$.

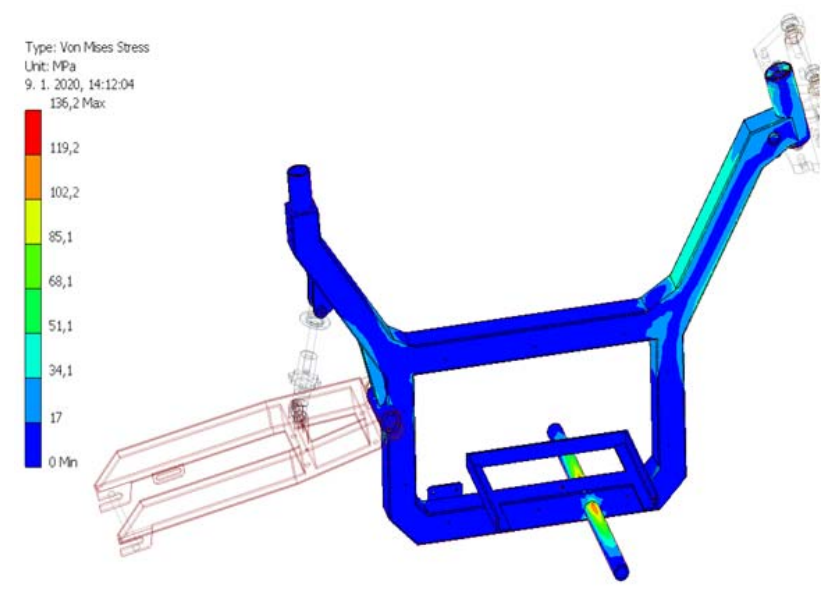

Figure 12. Frame stress analysis with gravity load, a driver stands on the footrests

Figure 13. shows the distribution of forces during braking. The force F4 acting on the frame is directly proportional to the deceleration (a) and mass (m) of the motorcycle with driver according to the equation $\mathrm{F}=$ ma. We considered the force $\mathrm{F}_{4}$ to be $800 \mathrm{~N}$. The forces $F_{1}, F_{2}, F_{3}$ are the weights of the driver, the electric motor and the battery.

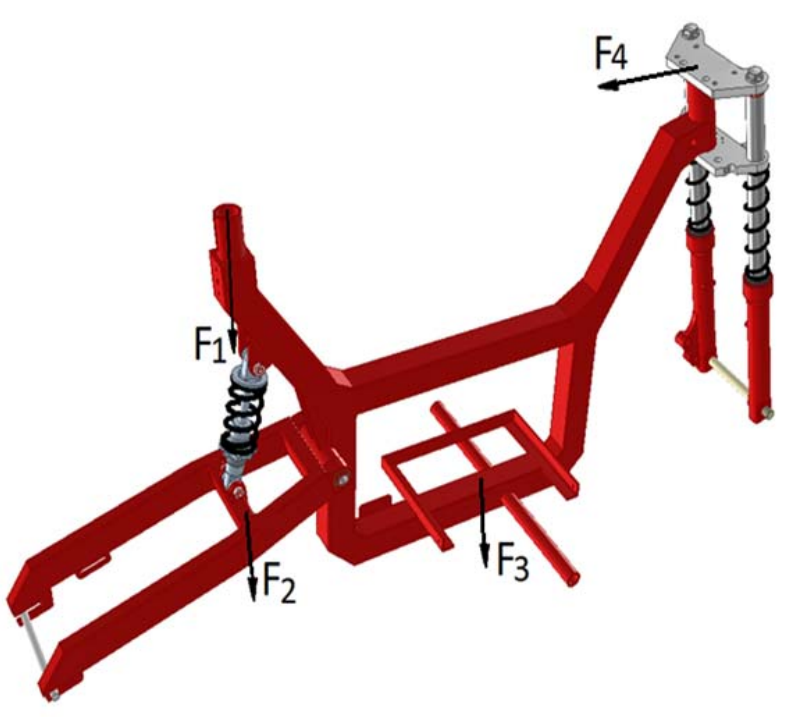

Figure 13. Distribution of forces during braking

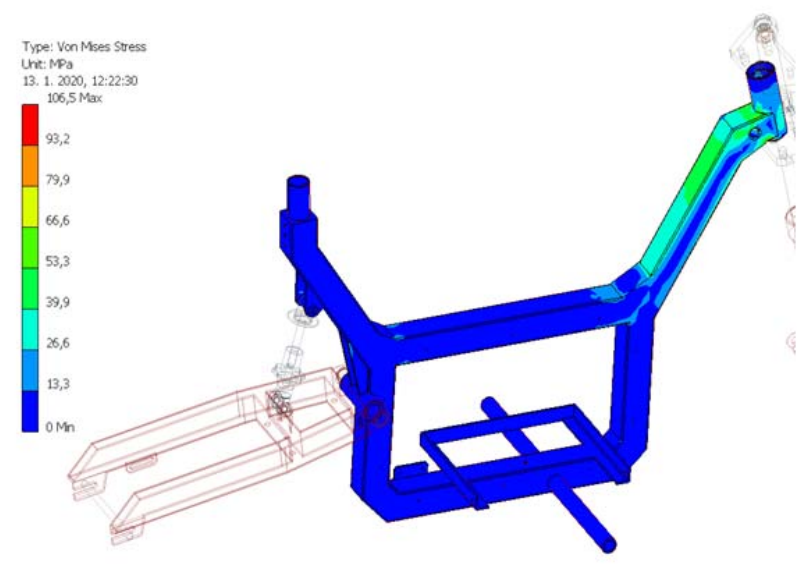

Figure 14. Frame stress analysis during braking

The Von Misses result in Figure 14. showed that the highest value was $106,5 \mathrm{MPa}$. This value is less than half compared to the minimum yield strength of $235 \mathrm{MPa}$ for S235JR steel. Safety factor is 2,2, which is acceptable. The greatest stress during braking is concentrated in the area of the steering axis and also around the hole for electrical cables.

We also analysed the rear swingarm. The rear swingarm is also made of steel S235JR as the frame. The main material for the production of the rear swingarm was square tube $20 \times 40 \mathrm{~mm}$ with a wall thickness of $3 \mathrm{~mm}$. Before simulation we fixed the motorcycle frame to the auxiliary plane. The forces $F_{1}(350 N)$ and $F_{2}(350 N)$ act on the rear swingarm as can be seen in Figure 15. We considered that the weight of the motorcycle and the driver is evenly distributed between the front and rear wheels. The sum of the forces $F_{1}$ and $F_{2}$ corresponds to half the weight of the driver and the motorcycle. 


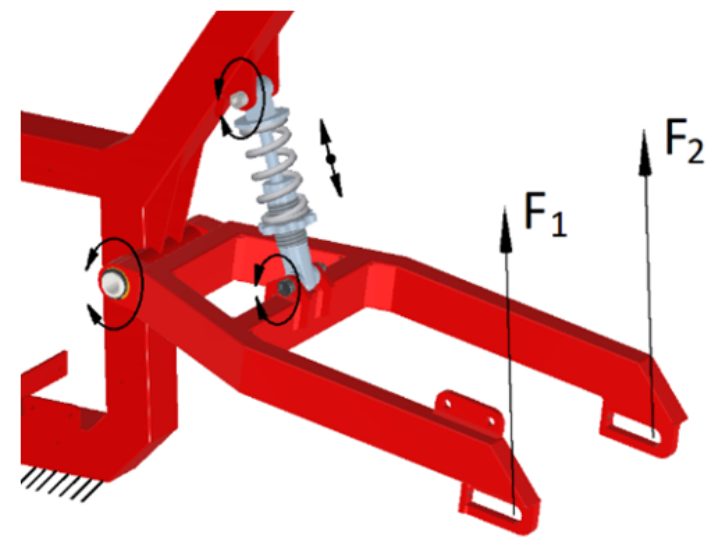

Figure 15. Force distribution at the rear swingarm

As Von Misses results showed, the first design of the rear swingarm had maximum stress of 98,26 $\mathrm{MPa}$ - Figure 16. We tried to modify the design of the rear swingarm to reduce maximum stress. We used reinforcements in places with the highest concentration of stress. In places where the stress was minimal, the square tube was replaced by flat steel bar. In both designs, the swingarms have approximately the same weight of $3,06 \mathrm{~kg}$, but the reinforced swingarm has a lower maximum stress of magnitude of 55,31 $\mathrm{MPa}$ - Figure 17.

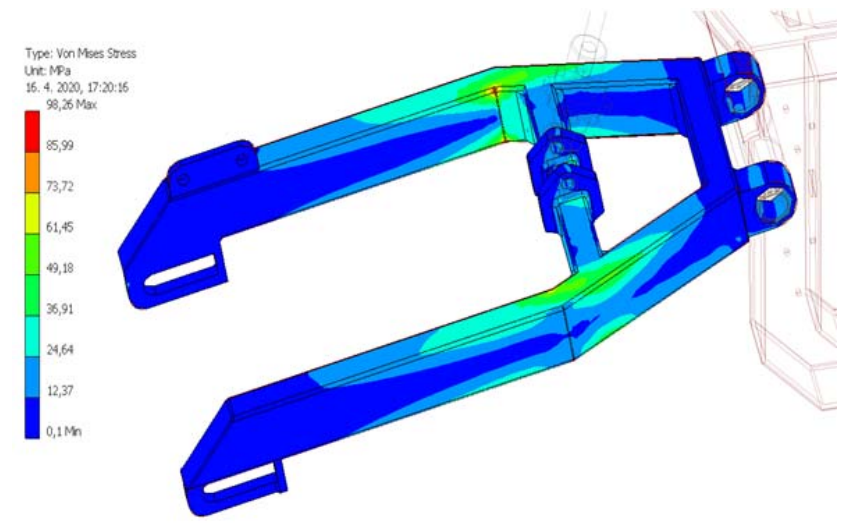

Figure 16. Swingarm stress analysis with gravity load

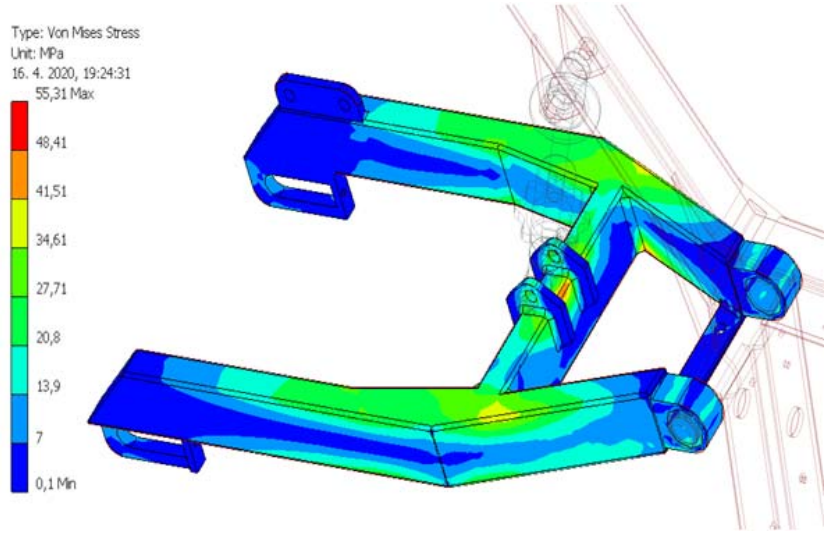

Figure 17. Swingarm stress analysis with gravity load after improving
However, we did not consider changing the weight distribution on the wheels and we also did not consider the dynamic load, for example when crossing uneven roads. These factors must also be taken into account for optimal design.

\section{Frame Production}

The production of the frame began by cutting steel square tubes on a band saw. The edges at the end of the square tubes were chamfered for welding. The tubes were inserted into the jig as you can see in Figure 18. The tubes were joined by several spot welds from the top and the sides. A TIG welder was used for welding. After removing the spot - welded frame from the jig, the welds were carefully completed around the perimeter of the tubes. This was followed by the addition of reinforcements in the next step. The reinforcements were made of the same square tubes as the frame. The steering head, seat tube and swingarm pivot tube were made on a CNC lathe. The footrests of the motorcycle were made of a round tube. The battery holder was made of L-shaped angle rods. The other small parts were made of steel plates. Welding of the frame was followed by grinding and painting.

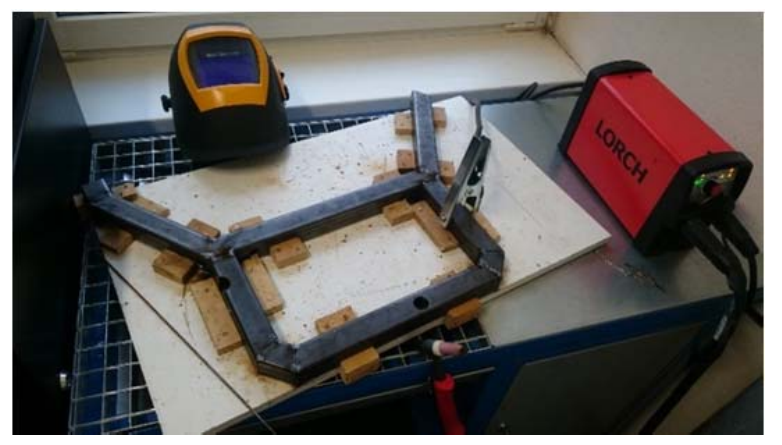

Figure 18. Production of a frame in a school workshop

In Figure 19. you can see the finished frame. The final shape of the frame differs from the first designs. Over time, we decided on a different type of battery and a different arrangement of components inside the motorcycle.

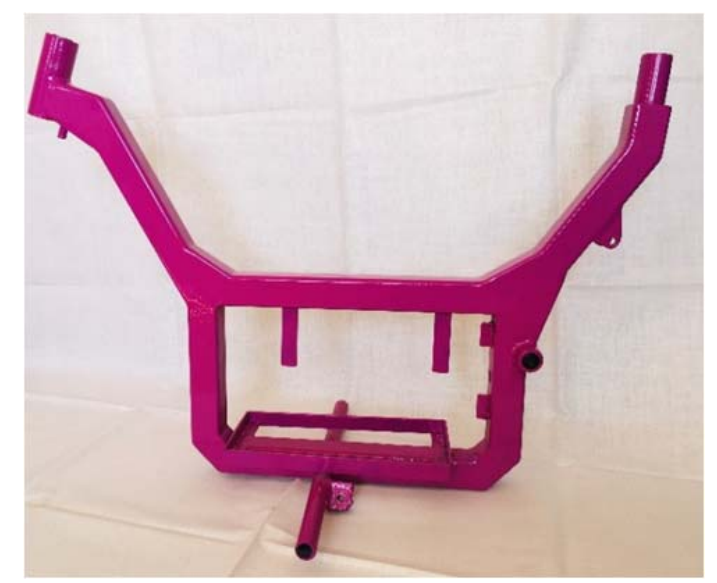

Figure 19. Finished frame of the electric motorcycle 


\section{Conclusion}

We have successfully produced a simple and cheap electric motorcycle frame. We used the commonly available structural steel S235JR. The weight of the frame without the rear swingarm is $8.2 \mathrm{~kg}$. The frame should be able to handle the weight of the motorcycle components and the weight of a $100 \mathrm{~kg}$ driver. Autodesk Inventor Professional 2020 simulation tools have allowed us to enhance the original frame design and rear swingarm design. We have optimized the choice of the wall thickness of the tubes for the production of the frame. In the case of the rear swingarm, we were able to reduce the maximum stress by $56 \%$ while maintaining the weight. After the production of the rear swingarm, the assembly of the electric motorcycle begins. We hope that the motorcycle will be reliably used for various experiments.

\section{References}

[1]. Bolton, C. E., \& Becker, S. A. (1985). Computer searching for patent information. World Patent Information, 7(1-2), 5-32.

[2]. Curry, C. (2017). Lithium-ion battery costs and market. Bloomberg New Energy Finance, 5, 4-6.

[3]. Vidyanandan, K. V., (2019). Batteries for Electric Vehicles. Published in: Energy Scan: A House eJournal of Corporate Planning, NTPC Ltd., vol. I (2019-20), no. 38, New Delhi, Jun 2019.

[4]. Vlk, F. (2004), Teorie a konstrukce motocyklu, ISBN 80-239-1601-7.

[5]. Foale, T. (2002), Motorcycle Handling and Chassis Design: The Art and Science, Spain: Tony Foale Designs., ISBN 8493328618.

[6]. Massaro, M., Cossalter, V., \& Cusimano, G. (2013). The effect of the inflation pressure on the tyre properties and the motorcycle stability. Proceedings of the Institution of Mechanical Engineers, Part D: Journal of automobile engineering, 227(10), 14801488.

[7]. Evangelou, S. A. (2010, September). Control of motorcycles by variable geometry rear suspension. In 2010 IEEE International Conference on Control Applications (pp. 148-154). IEEE. DOI: 10.1109/CCA.2010.5611082.

[8]. Stabla P., Zielonka P., (2018). Comparative analysis of the motorcycle subframe made of composite materials. The Book of Articles - National Scientific Conference "Nauka Badania Rozwój" II edition October 27, 2018, Warsaw.

[9]. Steel S235JR characteristics. Retrieved from: https://metinvestholding.com/en/products/steelgrades/s235jr [accessed: 15 March 2021].

[10]. Semrad, K. (2017). Aplikácia numerických simulačných metód v technickej praxi. ISBN 978-80553-3157-7.

[11]. Boardman B. (1990), Fatigue resistance of steels, ASM Handbook, Volume 1: Properties and Selection: Irons, Steels, and High-Performance Alloys.

[12]. Vlk, M. (1992). Dynamická pevnost a životnost. Vysoké učení technické. ISBN 80-214-0427-2. 